\title{
Mixed connective tissue disease associated with autoimmune hepatitis and thyroiditis
}

\author{
M Tomšič, V Ferlan-Marolt, T Kveder, S Hojker, B Rozman
}

\begin{abstract}
The case is reported of a 27 year old woman who had mixed connective tissue disease (MCTD) associated with chronic active hepatitis and thyroiditis. Although hepatomegaly is sometimes observed in MCTD, only four cases of MCTD and chronic active hepatitis have been described. It is thought that this is the first report of an association between MCTD, chronic active hepatitis and thyroiditis.
\end{abstract}

The association of mixed connective tissue disease (MCTD) and autoimmune hepatitis is rare. Only a few cases have been reported. ${ }^{1-3}$ MCTD associated with thyroiditis has not yet been described and it is suggested that the following case is the first example of a patient with MCTD and autoimmune hepatitis and thyroiditis.

\section{Case report}

A 27 year old woman was first admitted to this hospital in August 1988. She had had recurrent arthritis of the metacarpophalangeal and proximal interphalangeal joints after delivery in January 1988.

The initial clinical examination showed a diffuse enlarged thyroid gland and arthritis of both knees. Laboratory studies showed the following: erythrocyte sedimentation rate (Westergren) $32 \mathrm{~mm} /$ hour, leucocytes $3 \cdot 2 \times 10^{9} / 1$, serum gammaglobulin fraction $26 \cdot 8 \mathrm{~g} / \mathrm{l}$ (normal 5-15), serum aspartate aminotransferase 0.53 $\mu \mathrm{kat} / \mathrm{l}$ (normal $<0.60$ ), alanine aminotransferase $0.98 \mu \mathrm{kat} / \mathrm{l}($ normal $<0.70)$, alkaline phosphatase $1.48 \mu \mathrm{kat} / \mathrm{l}$ (normal $0.50-1.50$ ), total thyroxine $76 \mathrm{nmol} / 1$ (normal 53-182), triiodothyronine $2 \cdot 11 \mathrm{nmol} / \mathrm{l}$ (normal $1 \cdot 09-2 \cdot 62$ ), thyrotropin $4.08 \mathrm{mU} / 1$ (normal $0 \cdot 17-4 \cdot 05$ ).

An antinuclear antibody immunofluorescence test on mouse liver cryosections was positive at a titre of 1/40 and binding of double stranded DNA (Farr technique) was negative. Autoantibodies against intracellular antigens determined by a counterimmunoelectrophoresis test ${ }^{4}$ were highly positive for certain unidentified antibodies. Serum samples were negative for antibodies to U1RNP, Sm, Ro(SSA), and $\mathrm{La}(\mathrm{SSB})$ according to standard control antisera obtained from the Centre for Disease Control (Atlanta, GA, USA).

The Waaler-Rose and latex tests for rheumatoid factor, the Venereal Disease Research laboratory test, Coombs's test, lupus erythematosus cell phenomenon, and serum complement concentrations were within the normal range. Skin immunofluorescent studies (lupus band test) were negative. At that time no antibodies to thyroid could be detected, but because of a typical ultrasound pattern for chronic Hashimoto's thyroiditis treatment with thyroxine sodium ( $50 \mu \mathrm{g} /$ daily) was started. The patient was also treated with a non-steroidal anti-inflammatory drug (diclofenac sodium) and her symptoms disappeared.

Complete normalisation of thyrotropin concentrations was later established on regular control examinations. In June 1990, because of an enlarged lymphatic node near the righ thyroid lobe, a fine needle biopsy sample of the right lobe and the lymphatic node was obtained. Lymphocytic infiltration of the thyroid gland was found. At the same time increased titres of antibodies to microsomes $(1 / 1600)$ and tiroglobulin (1/40) were determined for the first time.

In October 1990 she was admitted again to this hospital because of fatigue and arthralgia of the knees, metacarpophalangeal and proximal interphalangeal joints. About two months before this second admission she developed Raynaud's phenomenon. There was no history of jaundice, exposure to toxins, blood transfusions, or alcohol or intravenous drug abuse. She was receiving levothyroxine sodium, diclofenac sodium, and oral contraceptives (norgestrel ethinyl estradiol).

Physical examination showed an enlarged thyroid gland, arthritis of both wrists, and puffy hands. The laboratory data obtained included: erythrocyte sedimentation rate $50 \mathrm{~mm} /$ hour, normal red and white blood cell and platelet counts, serum gammaglobulin fraction $39.3 \mathrm{~g} / \mathrm{l}$, aspartate aminotransferase $1.57 \mu \mathrm{kat} / 1$, alanine aminotransferase $2.53 \mu \mathrm{kat} / \mathrm{l}$, and alkaline phosphatase 2.00 $\mu \mathrm{kat} / \mathrm{l}$. Total bilirubin, albumin, serum copper, ceruloplasmin and $\alpha_{1}$ antitrypsin were normal. The hepatitis B surface antigen, hepatitis B surface and core antibodies, hepatitis $A$ and $C$ antibodies, and antibodies against cytomegalovirus and the Epstein-Barr virus were absent.

Antinuclear antibodies were strongly positive (titre greater than 1/320), and there were speckled pattern as well as antibodies to U1RNP (1/256) and unidentified antibodies. Antibodies to Sm, Ro(SSA), La(SSB), mitochondria, and centromere were negative, whereas antibodies against smooth muscle, determined by immunofluorescence on mouse stomach cryosections, were positive. The DNA binding capacity was 0.36 (normal $<0.35$ ). Serum complement concentrations were within the 
normal range. Anticardiolipin antibodies measured by an enzyme linked immunosorbent assay (ELISA) ${ }^{5}$ were low positive for IgG and negative for $\operatorname{IgM}$ anticardiolipin antibodies according to the Kingston antiphospholipid study reference serum sample.

After the withdrawal of oral contraceptives and diclofenac sodium the values of aspartate aminotransferase, alanine aminotransferase, and alkaline phosphatase returned to normal.

In November 1990 a percutaneous liver biopsy sample was taken. It showed chronic active hepatitis with fibrotic, moderately expanded portal tracts infiltrated chiefly with lymphocytes (fig 1). In some portal tracts the limiting plates were indistinct and partially destroyed by piecemeal necrosis (fig 2). Portal and septal fibrosis suggested an advanced chronic lesion that could progress to cirrhosis. Intralobular damage was characterised by sparse parenchymal necrosis and central fibrosis. Hepatitis B surface and core tissue antigens were negative. Treatment with 6-methylpred-

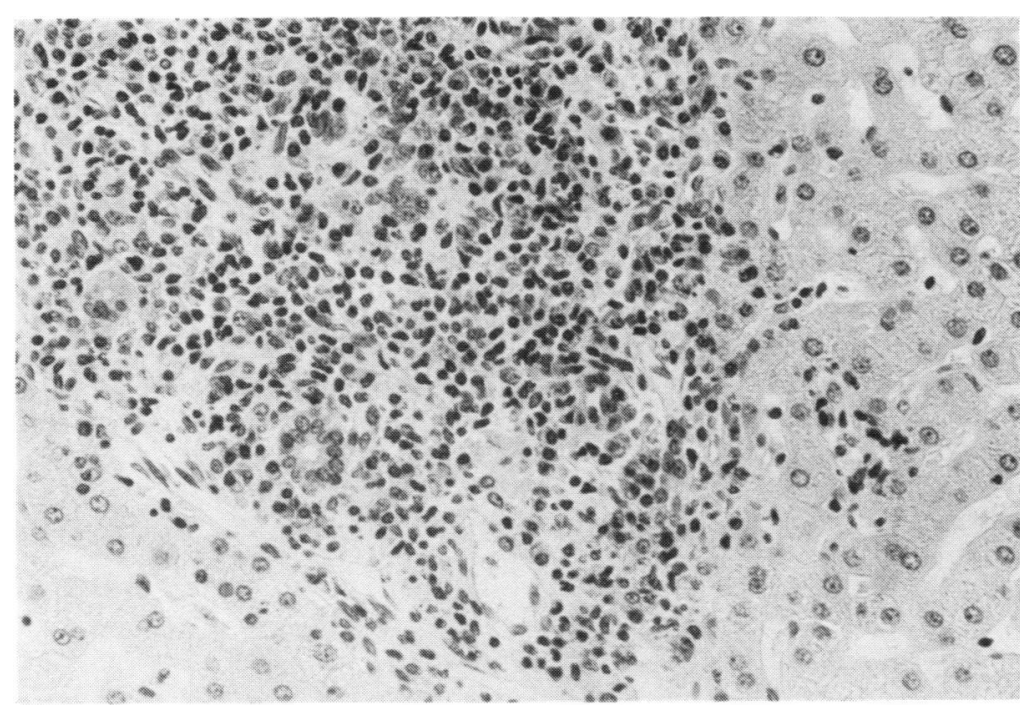

Figure 1 Dense inflammatory infiltration of the portal tract spreading to the periportal area and destroying the limiting plate. Needle biopsy, haematoxylin-eosin stain.

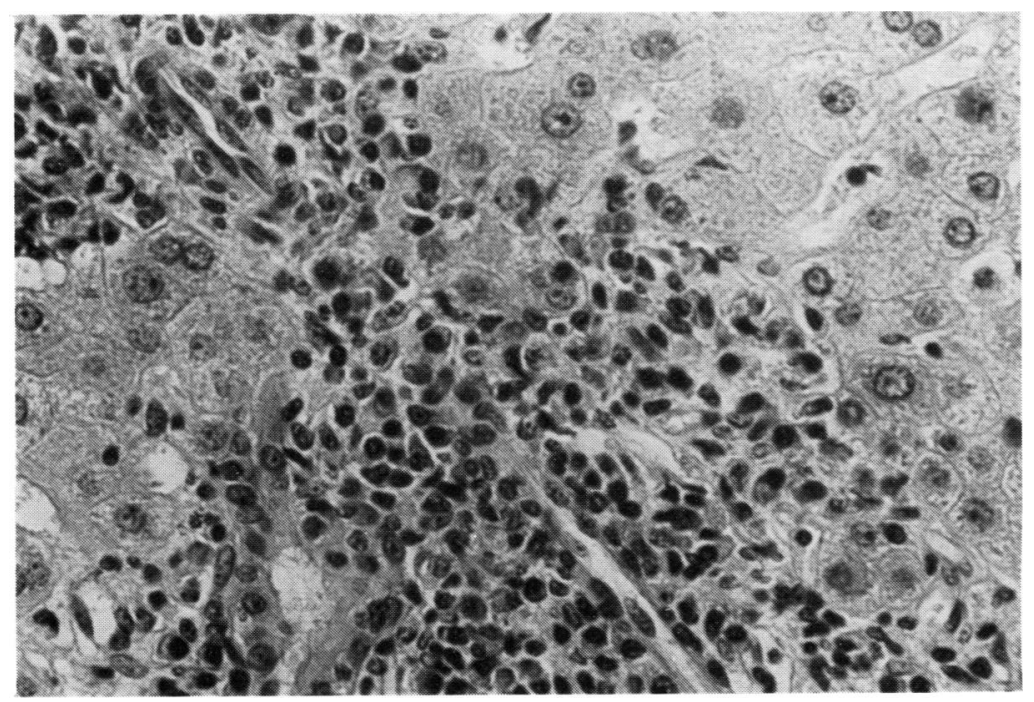

Figure 2 Fibrotic septum infiltrated with mononuclear inflammatory cells extending from the enlarged portal tract into the lobule, the peripheral margins of which are irregularly destroyed. Needle biopsy, haematoxylin-eosin stain. nisolone was started at a dose of $32 \mathrm{mg}$ daily; about three days later her fatigue and arthritis resolved, but the symptoms of Raynaud's phenomenon only slightly improved.

\section{Discussion}

Originally MCTD was described as a syndrome with overlapping clinical features similar to those of systemic lupus erythematosus, scleroderma, and polymyositis with high titres of antibodies to UIRNP and speckled antinuclear antibodies. $^{7}$

We describe herein a woman with MCTD (diagnosis based on three major criteriaRaynaud's phenomenon, swollen hands, high titres of antibodies to UIRNP and negative antibodies to $\mathrm{Sm}$; and two minor criteriaarthritis and leucopenia according to Porter et $a l{ }^{8}$ ) associated with autoimmune hepatitis and thyroiditis.

Viral infection as a cause of chronic active hepatitis (hepatitis A, B, C, cytomegalovirus and Epstein-Barr) was excluded. As the withdrawal of drugs (norgestrel ethinyl estradiol, diclofenac sodium) resulted in a complete normalisation of liver function, drug induced hepatitis as a cause of liver injury was considered. The histological findings, however, favoured immunological pathogenesis as they fulfilled the international histomorphological criteria for chronic active hepatitis of an immunological aetiology. ${ }^{9} 10$ The histological results, including advanced immune inflammation and fibrosis of periportal and septal regions in addition to an intralobular diffuse inflammatory process resembled autoimmune chronic active hepatitis and primary biliary cirrhosis in the precirrhotic stage. Histological markers for primary biliary cirrhosis, however, such as copper accumulation in hepatocytes and typical parabiliary granulomas, were not detected and antibodies to mitochondria were absent in the serum sample.

An exact histopathological distinction between autoimmune lesions and other kinds of hepatitis remained a diagnostic problem because the tissue antigens that would confirm such an aetiology were not detected. The histological findings, however, in addition to a prompt clinical response to treatment with corticosteroids, strongly supported the immunological pathogenesis of chronic active hepatitis.

It is possible that this patient had classical (lupoid) chronic autoimmune hepatitis, according to Manns and coworkers ${ }^{11}{ }^{12}$ even though liver membrane antibodies, liver kidney microsomal antibodies, and autoantibodies against soluble liver antigen were not determined.

Hepatomegaly, without serious functional disturbances, is reported to occur occasionally in patients with MCTD. ${ }^{7}{ }^{13}$ Marshall et al ${ }^{1}$ and Rolny et $a l^{2}$ described three patients with MCTD associated with severe inflammatory disease of the liver as a result of autoimmune chronic active hepatitis. The histological features included intensive mononuclear infiltration of the portal tracts, indistinctly limited because of piecemeal necroses. The patients showed chronic active hepatitis similar to the liver injury of our patient. Another patient with MCTD and parenchymal liver damage histologically 
different to these three cases was reported by Maeda et $a l .^{3}$ The liver histology showed remarkable degenerative parenchymal changes such as hydropic swelling, focal necrosis and disseminated formation of Councilman's bodies. The parenchymal damage prevailing over a slightly expressed inflammatory infiltration in the portal tracts could be interpreted as one of the stages of chronic active hepatitis.

Although there were no clinical signs and symptoms of thyroid dysfunction except a slightly enlarged thyroid gland, the diagnosis of chronic Hashimoto's thyroiditis on the basis of a typical ultrasound pattern was made and later confirmed by a fine needle biopsy and antibodies to thyroid. As thyrotropin concentrations measured with an ultrasensitive method were on the upper limit of the normal range, treatment with low dose thyroxine sodium was introduced. Sharp $e t a l^{7}$ described four of 25 patients with antibodies to thyroglobulin or thyroid disease, or both, but the thyroid disease was not evaluated correctly. We were also unable to find any other description of MCTD associated with thyroiditis. Liver and thyroid disease are rare in MCTD. The two diseases, however, due to a probable autoimmune aetiology, can complicate the course of MCTD.

The Kingston antiphospholipid study reference serum sample was kindly provided by Dr Nigel Harris.
1 Marshall J B, Ravendhran N, Sharp G C. Liver disease in mixed connective tissue disease. Arch Intern Med 1983; 143 1817-8.

2 Rolny P, Goobar J, Zettergren L. HB Ag-negative chronic active hepatitis and mixed connective tissue disease active hepatitis and mixed connective tis

3 Maeda M, Kanayama M, Hasumura Y, Takeuchi J, Uchida $\mathrm{T}$. Case of mixed connective tissue disease associated with autoimmune hepatitis. Dig Dis Sci 1988; 33: 1487-90.

4 Bunn C C, Gharavi A E, Hughes G R V. Antibodies to extractable nuclear antigens in 173 patients with DNA binding positive SLE: an association between antibodies to ribonucleoprotein and $\mathrm{Sm}$ antigens observed by counterimmunoelectrophoresis. F Clin Lab Immunol 1982; 8: 13-7

5 Loizou S, McCrea J D, Rudge J C, Reynolds R, Boyle C C, Harris E N. Measurement of anticardiolipin antibodies by an enzyme linked immunosorbent assay (ELISA). Standardisation and quantitation of results. Clin Exp Immunol 1985; 62: 738-45.

6 Gharavi A E, Harris E N, Asherson R A,. Hughes G R V. Anticardiolipin antibodies: isotype distribution and phospholipid specificity. Ann Rheum Dis 1987; 46: 1-6.

7 Sharp G C, Irvin W S, Tan E M, et al. Mixed connective tissue disease. An apparently distinct rheumatic disease syndrome associated with a specific antibody to an extractable nuclear antigen (ENA). Am $\mathcal{F}$ Med 1972; 52: 148-59.

8 Porter J F, Kingsland L C III, Lindberg D A B, et al. The A RHEUM knowledge-base computer consultant system in rheumatology. Arthritis Rheum 1988; 31: 219-26.

9 Boyer J L. Chronic hepatitis: a perspective on classification and determinates of prognosis. Gastroenterology 1976; 70 1161-71.

10 Boyer J L, Miller D J. Chronic hepatitis. In: Schiff L, Schiff $\mathrm{E} \mathrm{R}$, eds. Diseases of the liver. 6th ed. Philadelphia: Lippincott, 1987; 687-723.

11 Manns M, Gerken G, Kyriatsoulis A, et al. Characterisation of a new subgroup of autoimmune chronic active hepatitis of a new subgroup of autoimmune chronic active hepatitis by autoantibodies

12 Manns M P, Meyer zum Beschenfelde K H. Nature of autoantigens and autoantibodies in autoimmune hepatitis. Springer Semin Immunopathol 1990; 12: 57-65.

13 Prystowsky S D. Mixed connective tissue disease. West 7 Med 1980; 132: 288-93. 